\title{
Hubungan Sanitasi Dasar, Pengetahuan, Perilaku Dan Pendapatan Terhadap Kebiasaan Buang Air Besar Sembarangan Di Kelurahan Laksamana Wilayah Kerja Puskesmas Dumai Kota Tahun 2020
}

\author{
Sherly Vermita Warlenda, Ria Anggia Dwi Radifa, Nila Puspita Sari, Arief Wahyudi \\ Program Studi Sarjana Kesehatan Masyarakat \\ Corespondence Email : sherlyvermita130988@gmail.com
}

\begin{abstract}
Open defecation is the practice of disposing of feces in any open placeresults in environmental people who have not had proper sanitation, the community still conducts BABS. This is caused because they still have low knowledge and lack of information about the impact of open defecation. and The economy of the community is mainly one of the causes, because the community's work has not gotten enough results so that it is difficult for the community to make decent latrines. This study aims to determine factors related to basic sanitation, knowledge, attitudes and income towards the practice of open defecation in Laksamana Village, the working area of the Dumai Kota Health Center. This research uses Cross Sectional design and uses Stratified Random Sampling technique. Samples were 91 respondents. The independent variables in this study are toilet conditions, clean water sources knowledge, attitudes and income. The dependent variable is open defecation habits. From the Chi-Square statistical test results there is a relationship between toilet conditions with BABS that $(p=0.007)$, there is no relationship between clean water sources and BABS that $(p=$ 0.748), there is a relationship of knowledge with BABS that $(p=0.031)$, there is a relationship attitude with BABS that $(p=0.004)$, and there is an income relationship with that BABS $(p=0.005)$. Suggestions are expected by the community to reduce the habit of open defecation and familiarize the attitude to use the latrine so that the environment is clean and healthy.pollution.Based on data from the Dumai Kota Health Center, one of which is in Laksamana Village. Of the 811
\end{abstract}

Keywords : Sanitation, knowledge, behavior, income, BABS habits

Received: 30 April 2021, Accepted : Mai 2021 - Jurnal Photon Vol.11 No.2

DOI : https://doi.org/10.37859/jp.v17i2.2530

PHOTON is licensed under a Creative Commons Attribution-ShareAlike 4.0 International License 


\section{ABSTRAK}

Kebiasaan Buang Air Besar Sembarangan adalah praktik membuang tinja disembarang tempat terbuka yang mengakibatkan pencemaran lingkungan. Berdasarkan data dari Puskesmas Dumai Kota, salah satunya yaitu di Kelurahan Laksamana. Dari jumlah 811 jiwa yang memiliki sanitasi belum layak masyarakat masih melakukan BABS. Hal ini di sebabkan karena masih memiliki pengetahuan yang rendah dan kurangnya informasi tentang dampak dari BABS. dan Ekonomi masyarakat terutamanya menjadi salah satu penyebab, dikarenakan pekerjaan masyarakat tersebut belum mendapatkan hasil yang cukup sehingga memungkinkan masyarakat sulit untuk membuat jamban yang layak. Penelitian ini bertujuan untuk mengetahui faktor yang berhubungan sanitasi dasar, pengetahuan, sikap dan pendapatan terhadap kebiasaan BABS di Kelurahan Laksamana wilayah kerja Puskesmas Dumai Kota. Penelitian ini menggunakan desai Cross Sectional dan menggunakan teknik sampel Stratified Random Sampling. Sampel sebanyak 91 responden. Variabel Independen pada penelitian ini adalah kondisi jamban, sumber air bersih, pengetahuan, sikap dan pendapatan. Variabel dependen adalah kebiasaan buang air besar sembarangan. Dari hasil uji statistik Chi-Square terdapat hubungan antara kondisi jamban dengan BABS bahwa ( $\mathrm{p}=0,007)$, tidak terdapat hubungan sumber air bersih dengan BABS bahwa $(\mathrm{p}=0,748)$, terdapat hubungan pengetahuan dengan BABS bahwa $(\mathrm{p}=0,031)$, terdapat hubungan sikap dengan BABS bahwa $(\mathrm{p}=0,004)$, dan terdapat hubungan pendapatan dengan BABS bahwa $(\mathrm{p}=0,005)$. Saran yang diharapkan masyarakat untuk mengurangi kebiasaan BABS dan membiasakan sikap untuk memanfaatkan jamban agar kondisi lingkungan bersih dan sehat.

Kata Kunci : Sanitasi, pengetahuan, perilaku, pendapatan, kebiasaan BABS

Received: 30 April 2021, Accepted : Mai 2021 - Jurnal Photon Vol.11 No.2

DOI : https://doi.org/10.37859/jp.v11i2.2530

PHOTON is licensed under a Creative Commons Attribution-ShareAlike 4.0 International License 


\section{Introduction}

Kurangnya sanitasi serta pembuangan tinja secara sembarangan adalah salah satu faktor yang menyebabkan masyarakat melakukan BABS yang akan memberikan efek yang buruk, berkaitan dengan penularan beberapa penyakit infeksi yaitu penyakit diare, kolera, typhoid fever, dan paratyphoid fever, disentri, penyakit cacing tambang, ascariasis, hepatitis A dan E, penyakit kulit, trakhoma, schistosomiasis, cryptosporidiosis, malnutrisi, dan penyakit yang berhubungan dengan malnutrisi.kasus kesakitan pertahun di Indonesia akibat sanitasi buruk adalah penyakit diare sebesar $72 \%$, kecacingan $0,85 \%$, scabies $23 \%$, trachoma 0,14\%, Hepatitis A 0,57\%,Hepatitis E 0,02\% dan Malnutrisi 2,5\%, sedangkan kasus kematian akibat sanitasi buruk adalah diare sebesar 46\%, kecacingan 0,1\%, scabies 1,1\%, hepatitis A 1,4\% dan hepatitis E 0,04\% (Kemenkes RI, 2015).

Dampak dari banyaknya penduduk Indonesia yang membuang air besar sembarangan adalah menyebabkan diare yaitu karena lalat yang hinggap pada tinja akan membawa kuman atau bakteri kepada makanan yang akan mereka makan. Memiliki kebiasaan tidak mencuci tangan menggunakan sabun dengan baik dan benar, maka kuman atau bakteri tersebut akan masukke dalam sistem pencernaan sehingga mengakibatkan penyakit. Dampak dari buang air besar sembarangan dapat mencemari air, kotoran yang dibuang ke sungai atau rawa-rawa secara sembarangan dapat mencemari air, air yang tercemar kotoran manusia itu bisa mengandung bakteri E. coli. air yang sudah tercemar bakteri tidak bisa digunakan lagi (Shoim Anwar et, al, 2017).

Berdasarkan data BABS Kota Dumai tahun 2018-2019 untuk wilayah Kecamatan Dumai Kota yang terdiri dari 5 Kelurahan dan diketahui masyarakatnya memiliki kebiasaan buang air besar sembarangan (BABS). Dari 5 Kelurahan di Kecamatan Dumai Kota memiliki Desa Stop BABS terdapat 3 Kelurahan sebesar (60.00\%). Sisnya 2 Kelurahan yang masih melakukan buang air besar sembarangan yaitu Kelurahan Rimba Sekampung sebesar $(79,17 \%)$ dan yang terendah yaitu Kelurahan Laksamna sebesar (42,86 \%) (Profil Dinkes dan Puskesmas Dumai Kota, 2019). Wilayah kerja Puskesmas Dumai Kota, khususnya di Kelurahan Laksamana yang beberapa masyarakatnya masih melakukan BABS dapat diketahui bahwa dari 3 tahun terakhir masyarakat yang memiliki jamban, jumlah 4,042 jiwa, terdapat (96\%) 2,683 jiwa yang memiliki jamban leher angsa memenuhi syarat, (66,53\%) 332 jiwa yang memiliki jamban plengsengan memenuhi syarat, (45\%) 216 jiwa yang memiliki jamban cemplung memenuhi syarat, dan untuk penduduk dengan sanitasi yang layak sebanyak3231 jiwa, sedangkan untuk penduduk yang memiliki sanitasi yang tidak layak sebanyak 811 jiwa. Hasil observasi pendahuluan yang dilakukan di daerah kelurahan Laksamana dari 3 tahun terakhir masih terdapat beberapa penduduk yang memanfaatkan sungai, parit dan jamban untuk membuang

Received: 30 April 2021, Accepted : Mai 2021 - Jurnal Photon Vol.11 No.2

DOI : https://doi.org/10.37859/jp.v11i2.2530

PHOTON is licensed under a Creative Commons Attribution-ShareAlike 4.0 International License 
kotoran/tinja (Profil Puskesmas, 2019).

Berdasarkan survei awal yang saya lakukan di Kelurahan Laksamana wilayah kerja Puskesmas Dumai Kota masih terdapat masyarakat yang masih melakukan buang air besar sembarangan.Dari 5 orang yang saya wawancarai 3 diantaranya masih memiliki pengetahuan rendah dan kurangnya informasi tentang dampak dari buang air besar sembarangan. Tanggapan masyarakat akan hal ini adalah untuk membuat jamban yang memenuhi syarat membutuhkan biaya yang mahal, sehingga buang air besar sembarangan menjadi tindakan yang mudah dan jarak rumah dekat dengan sungai/rawa. Ekonomi masyarakat terutamanya menjadi salah satu penyebab, dikarenakan pekerjaan masyarakat di Kelurahan tersebut belum mendapatkan hasil yang cukup sehingga memungkinkan masyarakat sulit untuk membuat jamban dan lebih mudah untuk melakukan buang air besar sembarangan. Tujuan penelitian untuk mengetahui Hubungan Sanitasi Dasar, Prilaku dan Pendapatan Terhadap Kebiasaan Buang Air Besar Sembarangan Di Kelurahan Laksamana Wilayah Kerja Puskesmas Dumai Kota Tahun 2020.

\section{The Methods}

Penelitian ini merupakan jenis penelitian kuantitatif yaitu penelitian yang menekankan pada data numerik dan diolah dengan metode statistika Desain yang digunakan adalah Desain Cross Sectional, dilaksanakan di KelurahanLaksamanaKecamatanDumai Kota padabulan juni sampai juli 2020. penelitian ini yang menjadi populasi adalah seluruh keluarga yang memiliki kebiasaan buang air besar sembarangan di KelurahanLaksamanaberjumlah 1082 KK dari 7 RT dengan sampel 91 responden. Analisis univariat dilakukan untuk menjelaskan atau menggambarkan karakteristik setiap variabel penelitian. Analisa bivariate dilakukan terhadap dua variabel yaitu variabel bebas dan terikat yang diduga berhubungan dengan menggunakan uji Chi-Square yangtingkat kepercayaannya adalah $1 \%(\alpha=0,01)$ dan menggunakan program komputer SPSS.

\section{Result and Discussion}

Berdasarkan tabel 1 diketahui distribusi karaktristik responden di Kelurahan Laksamana menurut jenis kelamin, dimana rata-rata jenis kelamin responden laki-laki adalah 82 (90.1\%) dan perempuan sebanyak 9 (9.9\%). karaktristik responden menurut umur, dimana rata-rata umur responden yang tertinggi 36-54 sebanyak 62 (68.\%), dan yang terendah diumur >20-35 adalah 12 (13.2\%). Menurut pendidikan responden yang tertinggi yaitu SD-SMP sebanyak $42(46.2 \%)$, dan pendidikan yang terendah yaitu perguruan tinggi $8(8.8 \%)$. Menurut pekerjaan, dimana rata-rata mayoritas pekerjaan responden yang tertinggi adalah buruh sebanyak 40 (44.0\%), dan yang terendah adalah tidak berkerja sebanyak 4 (4.4\%).

Received: 30 April 2021, Accepted : Mai 2021 - Jurnal Photon Vol.11 No.2

DOI : https://doi.org/10.37859/jp.v11i2.2530 
Tabel 1.

Distribusi Frekuensi Responden Berdasarkan Variabel pada Masyarakat di Kelurahan Laksamana Tahun 2020

\begin{tabular}{|c|c|c|c|}
\hline \multirow{2}{*}{ No } & \multirow{2}{*}{ Variabel } & \multicolumn{2}{|c|}{ Proposi } \\
\hline & & $\mathbf{n}$ & $\%$ \\
\hline \multirow[t]{3}{*}{1} & Jenis kelamin & & \\
\hline & a. Laki-laki & 82 & 90.1 \\
\hline & b. Perempuan & 9 & 9.9 \\
\hline \multirow[t]{4}{*}{2} & Umur & & \\
\hline & a. $>20-35$ & 12 & 13.2 \\
\hline & b. $36-54$ & 62 & 68.1 \\
\hline & c. $\quad 55-70$ & 17 & 18.7 \\
\hline \multirow[t]{5}{*}{3} & Pendidikan & & \\
\hline & a. SD-SMP & 42 & 46.2 \\
\hline & b. SMA & 41 & 45.1 \\
\hline & c. Perguruan & 8 & 8.8 \\
\hline & Tinggi & & \\
\hline \multirow[t]{7}{*}{4} & Pekerjaan & & \\
\hline & a. PNS & 6 & 6.6 \\
\hline & b. Wiraswata & 16 & 17.6 \\
\hline & c. Petani & 15 & 16.5 \\
\hline & d. Buruh & 40 & 44.0 \\
\hline & e. Nelayan & 10 & 11.0 \\
\hline & f. Tidak Berkerja & 4 & 4.4 \\
\hline
\end{tabular}

Tabel 2

Hasil Analisis Univariat Hubungan Sanitasi Dasar, Prilaku dan Pendapatan Terhadap Kebiasaan Buang Air Besar SembaranganDi Kelurahan Laksamana Wilayah

Kerja Puskesmsas Dumai Kota Tahun 2020

\begin{tabular}{|c|c|c|c|c|c|c|c|c|}
\hline \multirow{3}{*}{ Kondisi Jamban } & \multicolumn{6}{|c|}{ Buang Air Besar Sembarangan } & \multirow{3}{*}{$\begin{array}{c}\mathrm{P} \\
\text { Value }\end{array}$} & \multirow{3}{*}{$\begin{array}{c}\text { OR } \\
(95 \% \mathrm{CI})\end{array}$} \\
\hline & \multicolumn{2}{|c|}{ BABS } & \multicolumn{2}{|c|}{ Tidak BABS } & \multicolumn{2}{|c|}{ Total } & & \\
\hline & $\mathrm{N}$ & $\%$ & n & $\%$ & $\mathbf{n}$ & $\%$ & & \\
\hline \multirow{2}{*}{$\begin{array}{l}\text { Tidak Memenuhi } \\
\text { Syarat } \\
\text { Memenuhi Syarat }\end{array}$} & 28 & 0.0 & 12 & 30.0 & 40 & 100 & \multirow{3}{*}{0,007} & 3.617 \\
\hline & 20 & 9.2 & $\underline{31}$ & $\underline{60.8}$ & $\underline{51}$ & 100 & & $8.714)$ \\
\hline \multirow[t]{2}{*}{ Jumlah } & 48 & 2.7 & 43 & 47.3 & 91 & 100 & & \\
\hline & \multicolumn{6}{|c|}{ Tabel 3} & & \\
\hline \multirow{3}{*}{ Sumber Air Bersih } & \multicolumn{6}{|c|}{ Buang Air Besar Sembarangan } & \multirow{3}{*}{$\begin{array}{c}\mathrm{P} \\
\text { Value }\end{array}$} & \multirow{3}{*}{$\begin{array}{l}\text { OR } \\
(95 \% \mathrm{CI})\end{array}$} \\
\hline & \multicolumn{2}{|c|}{ BABS } & \multicolumn{2}{|c|}{ Tidak BABS } & \multicolumn{2}{|c|}{ Total } & & \\
\hline & $\mathrm{N}$ & $\%$ & $\mathbf{n}$ & $\%$ & $\mathbf{n}$ & $\%$ & & \\
\hline \multirow{2}{*}{$\begin{array}{l}\text { Tidak } \\
\text { MemenuhiSyarat } \\
\text { Memenuhi Syarat }\end{array}$} & 23 & 50.0 & 23 & 50.0 & 46 & 100 & \multirow{2}{*}{0,748} & $\begin{array}{l}0.800 \\
(0.35\end{array}$ \\
\hline & 25 & 55.6 & 20 & 44.4 & 45 & 100 & & $1-$ \\
\hline
\end{tabular}

Received: 30 April 2021, Accepted : Mai 2021 - Jurnal Photon Vol.11 No.2 DOI : https://doi.org/10.37859/jp.v11i2.2530

PHOTON is licensed under a Creative Commons Attribution-ShareAlike 4.0 International License 


\begin{tabular}{llllllll}
\hline Jumlah & 48 & 52.7 & 43 & 47.3 & 91 & 100 & $\begin{array}{c}1.825 \\
)\end{array}$ \\
\hline
\end{tabular}

Tabel 4

\begin{tabular}{|c|c|c|c|c|c|c|c|c|}
\hline \multirow{3}{*}{ Pengetahuan } & \multicolumn{6}{|c|}{ Buang Air Besar Sembarangan } & \multirow{3}{*}{$\begin{array}{c}\mathrm{P} \\
\text { Value }\end{array}$} & \multirow{3}{*}{$\begin{array}{c}\text { OR } \\
(95 \% \mathrm{CI})\end{array}$} \\
\hline & \multicolumn{2}{|c|}{ BABS } & \multicolumn{2}{|c|}{$\begin{array}{l}\text { Tidak } \\
\text { BABS }\end{array}$} & \multicolumn{2}{|c|}{ Total } & & \\
\hline & $\mathrm{N}$ & $\%$ & $\mathrm{n}$ & $\%$ & n & $\%$ & & \\
\hline Rendah & 32 & 64.0 & 18 & 36.0 & 50 & 100 & & 2.778 \\
\hline Tinggi & $\underline{16}$ & 39.2 & 25 & 61.0 & 41 & 100 & 0,031 & (1.184- \\
\hline Jumlah & 48 & 52.7 & 43 & 47.3 & 91 & 100 & & $6.514)$ \\
\hline
\end{tabular}

Tabel 5

\begin{tabular}{|c|c|c|c|c|c|c|c|c|}
\hline \multirow{3}{*}{ Sikap } & \multicolumn{6}{|c|}{ Buang Air Besar Sembarangan } & \multirow{3}{*}{$\begin{array}{c}\mathrm{P} \\
\text { Value }\end{array}$} & \multirow{3}{*}{$\begin{array}{c}\text { OR } \\
(95 \% \mathrm{CI})\end{array}$} \\
\hline & \multicolumn{2}{|c|}{ BABS } & \multicolumn{2}{|c|}{$\begin{array}{l}\text { Tidak } \\
\text { BABS }\end{array}$} & \multicolumn{2}{|c|}{ Total } & & \\
\hline & $\mathrm{N}$ & $\%$ & $\mathbf{n}$ & $\%$ & $\mathbf{N}$ & $\%$ & & \\
\hline Negatif & 29 & 70.7 & 12 & 29.3 & 41 & 100 & & 3.943 \\
\hline Positif & 19 & 38.0 & 31 & 62.0 & $\underline{50}$ & 100 & 0,004 & $9.529)$ \\
\hline Jumlah & 48 & 52.7 & 43 & 47.3 & 91 & 100 & & \\
\hline
\end{tabular}

Tabel 6

\begin{tabular}{|c|c|c|c|c|c|c|c|c|}
\hline \multirow{3}{*}{ Pendapatan } & \multicolumn{6}{|c|}{ Buang Air Besar Sembarangan } & \multirow{3}{*}{$\begin{array}{c}\mathrm{P} \\
\text { Value }\end{array}$} & \multirow{3}{*}{$\begin{array}{c}\text { OR } \\
(95 \% \mathrm{CI})\end{array}$} \\
\hline & \multicolumn{2}{|c|}{ BABS } & \multicolumn{2}{|c|}{$\begin{array}{l}\text { Tidak } \\
\text { BABS }\end{array}$} & \multicolumn{2}{|c|}{ Total } & & \\
\hline & $\mathrm{N}$ & $\%$ & $\mathrm{~N}$ & $\%$ & $\mathbf{n}$ & $\%$ & & \\
\hline Rendah & 35 & 66.0 & 18 & 34.0 & 53 & 100 & & $\begin{array}{r}3.739 \\
1552\end{array}$ \\
\hline Tinggi & $\underline{13}$ & $\underline{34.2}$ & $\underline{25}$ & 65.8 & $\underline{38}$ & 100 & 0,005 & 9.004) \\
\hline Jumlah & 48 & 52.7 & 43 & 47.3 & 91 & 100 & & \\
\hline
\end{tabular}

\section{Hubungan kondisi Jamban terhadap Kebiasaan Buang Air Besar Sembarangan}

Berdasarkan tabel 3 diatas didapatkan hasil bahwa kondisi jamban yang tidak memenuhi syarat dengan buang air besar sembarangan (BABS) sebanyak 28 (70.0\%), dan untuk kondisi jamban yang memenuhi syarat sebanyak 20 $(39,2 \%)$. Dari hasil uji statistik menggunakan Chi Square diperoleh P value $=0,007<\alpha 0,05$, artinya ada hubungan yang bermakna kondisi jamban terhadap kebiasaan buang air besar sembarangan (BABS).

Dari hasil analisis diperoleh $\mathrm{OR}=3,617$ yang artinya responden dengan kondisi jamban yang tidak memenuhi syarat diperkirakan 3,6 kali lebih berisiko untuk kebiasaan buang air besar sembarangan dibandingkan dengan responden yang memiliki kondisi jamban yang memenuhi syarat.

Received: 30 April 2021, Accepted : Mai 2021 - Jurnal Photon Vol.11 No.2 DOI : https://doi.org/10.37859/jp.v11i2.2530 


\section{Hubungan Sumber Air Bersih terhadap Kebiasaan Buang Air Besar Sembarangan}

Berdasarkan tabel 4 diatas didapatkan hasil bahwa sumber air bersih yang tidak memenuhi syarat dengan buang air besar sembarangan (BABS) sebanyak 23 (50.0\%), dan untuk kondisi jamban yang memenuhi syarat sebanyak 25 $(55,6 \%)$.

Dari hasil uji statistik menggunakan Chi Square diperoleh $\mathrm{P}$ value $=0,748<\alpha 0,05$, artinya tidak ada hubungan yang bermakna sumber air bersih terhadap kebiasaan buang air besar sembarangan (BABS). Dari hasil analisis diperoleh $\mathrm{OR}=0,748$ yang artinya responden dengan sumber air bersih yang tidak memenuhi syarat diperkirakan 0,7 kali pencegahan faktor resiko terhadap kebiasaan buang air besar sembarangan dibandingkan dengan responden yang memiliki sumber air bersih yang memenuhi syarat.

\section{Hubungan pengetahuan terhadap Kebiasaan Buang Air Besar Sembarangan}

Berdasarkan tabel 5 diatas didapatkan hasil bahwa responden yang memiliki pengetahuan yang rendah dengan buang air besar sembarangan (BABS) sebanyak 32(64.0\%), dan pengetahuan yang tinggi sebanyak 16(39,2\%). Dari hasil uji statistik menggunakan Chi Square diperoleh $P$ value $=0,031<a 0,05$, artinya ada hubungan yang bermakna pengetahuan terhadap kebiasaan buang air besar sembarangan (BABS).

Dari hasil analisis diperoleh $\mathrm{OR}=2.778$ yang artinya responden dengan pengetahuan yang rendah diperkirakan 2,7 kali lebih berisiko untuk kebiasaan buang air besar sembarangan dibandingkan dengan responden yang memiliki pengetahuan yang tinggi.

\section{Hubungan Sikap terhadap Kebiasaan Buang Air Besar Sembarangan}

Berdasarkan tabel 6 diatas didapatkan hasil bahwa responden yang memiliki sikap negatif dengan buang air besar sembarangan (BABS) sebanyak 29 (70.7\%), dan sikap yang positif sebanyak 19 (38,0\%).

Dari hasil uji statistik menggunakan Chi Square diperoleh $\mathrm{P}$ value $=0,004<\alpha 0,05$, artinya ada hubungan yang bermakna sikap terhadap kebiasaan buang air besar sembarangan (BABS). Dari hasil analisis diperoleh OR $=3.943$ yang artinya responden dengan sikap yang negatif diperkirakan 3.9 kali lebih berisiko untuk kebiasaan buang air besar sembarangan dibandingkan dengan responden yang memiliki sikap yang positif.

\section{Hubungan Pendapatan terhadap Kebiasaan Buang Air Besar Sembarangan}

Berdasarkan tabel 7 diatas didapatkan hasil bahwa pendapatan yang rendah dengan buang air besar sembarangan (BABS) sebanyak 35 (66.0\%), dan pendapatan yang tinggi sebanyak 13(34,2\%).

Dari hasil uji statistik menggunakan Chi Square diperoleh P value $=0,005<\alpha 0,05$, artinya ada hubungan yang bermakna pendapatan terhadap kebiasaan buang air besar sembarangan (BABS).

Received: 30 April 2021, Accepted : Mai 2021 - Jurnal Photon Vol.11 No.2

DOI : https://doi.org/10.37859/jp.v17i2.2530

PHOTON is licensed under a Creative Commons Attribution-ShareAlike 4.0 International License 
Dari hasil analisis diperoleh $\mathrm{OR}=3.739$ yang artinya responden dengan pendapatan yang rendah diperkirakan 3.7 kali lebih berisiko untuk kebiasaan buang air besar sembarangan dibandingkan dengan responden yang memiliki pendapatan yang tinggi.

\section{PEMBAHASAN}

\section{Hubungan Kondisi Jamban Terhadap Kebiasaan Buang Air Besar Sembarangan}

Dari hasil penelitian di dapatkan bahwa ada hubungan yang bermakna antara kondisi jamban terhadap kebiasaan buang air besarsembarangan di Kelurahan Laksamana wilayah kerja Puskesmas Dumai Kota Tahun 2020. Hasil ini didukung dengan $\mathrm{p}$ value $=0,007<a$ 0,05.dan dilihat dari nilai OR sebesar (3.617) artinya masyarakat dengan kondisi jamban yang tidak memenuhi syarat beresiko 3.617 kali untuk Buang Air Besar Sembarangan dibandingkan dengan kondisi jamban yang memenuhi syarat.

Dari hasil observasi penelitian pada responden di Kelurahan Laksamana tidak seluruh sanitasi dasar yang memenuhi syarat. Pada observasi terdapat kondisi jamban yang tidak mempunyai syarat sebanyak 28(70.0\%). Banyak responden yang tidak memiliki jamban sesuai persyaratan sehingga hal ini dapat mengakibatkan masyarakat melakukan BABS di sungai. Masyarakat yang memiliki kondisi jamban yang tidak memenuhi syarat seperti contoh jamban yang tersumbat, jamban yang tidak permanen, dan jamban yang tidak memiliki saluran septic tank, membuat masyarakat akan merasa tidak nyaman untuk melakukan BAB di jamban milik sendiri, masyarakat lebih memilih melakukan $\mathrm{BAB}$ di sungai atau disembarangan tempat dibandingkan milik sendiri karena akan lebih praktisjika melakukan di rumah masyarakat harus membersihkan jamban tersebut. Sedangkan untuk masyarakat yang memiliki jamban yang memenuhi syarat namun masih melakukan BABS dikarenakan hal itu sudah menjadi tradisi dari yang terdahulu. Faktor ekonomi juga sangat mempengaruhi akan hal ini, bagi masyarakat yang tidak memiliki jamban akan lebih banyak peluang untuk melakukan BABS di sungai, karena untuk membuat sebuah jamban akan membutuhkan biaya yang besar sedangkan perekonomian masyarakat rendah.

Berdasarkan hasil Penelitian yang dilakukan oleh Febri Anggoro (2015), bahwa terdapat hubungan antara kondisi jamban dengan kebiasaan buang air besar sembarangan dengan $\mathrm{p}$ value $=0,001<\alpha 0,005$, dimana berdasarkan tingkat ekonomi yang rendah masyarakat tidak mampu untuk membuat jamban, tingkat pendidikan yang rendah juga mempengaruhi dikarenakan masyarakat tidak mengetahui fungsi jamban dan syarat jamban sehat dengan baik. ketersediaan akses sanitasi dasar seperti jamban juga berpengaruh terhadap perilaku masyarakat dalam berhenti untuk tidak BABS.

Jamban merupakan suatu kebutuhan pokok manusia yang berguna untuk memelihara kesehatan dengan

Received: 30 April 2021, Accepted : Mai 2021 - Jurnal Photon Vol.11 No.2

DOI : https://doi.org/10.37859/jp.v17i2.2530

PHOTON is licensed under a Creative Commons Attribution-ShareAlike 4.0 International License 
mengadakan lingkungan yang bersih dan sehat. Jamban tidak diperbolehkan menimbulkan bau tidak sedap dan kontruksi jamban harus kokoh dengan biaya yang terjangkau. Menurut Kementerian Kesehatan Republik Indonesia No. 03/MENKES/SK/IX/2014 tentang strategi nasional sanitasi total berbasis masyarakat, dimana hal ini dilakukan untuk pendekatan agar perilaku masyarakat berubah melalui pemberdayaan masyarakat. STBM terdiri dari lima pilar yaitu, stop BABS, CTPS, pengelolaan air minum dan makanan rumah tangga dan pengamanan sampah rumah tangga serta pengamanan limbah cair rumah tangga. Perilaku stop BABS bertujuan untuk membudayakan perilaku $\mathrm{BAB}$ sehat untuk memutus alur kontaminasi kotoran manusia sebagai sumber penyakit dan menyediakan serta memelihara sarana $\mathrm{BAB}$ yang memenuhi standar dan perasyarakat kesehatan. Jamban sehat adalah fasilitas pembuangan tinja yang efektif yang bertujuan untuk memutuskan mata rantai penularan penyakit.

Pembuangan tinja yang semakin banyak memicu karena pertambahan penduduk yang tidak sebanding dengan pemukiman yang tersedia membuat masalah pembuangan kotoran yang terus meningkat. Segi kesehatan masyarakat untuk masalah tinja ini merupakan halyang harus segera diatasi, karena tinja manusia adalah sumber penyakit yang dapat menyebarkan penyakit dengan sangat kompleks melalui berbagai cara, misalnya air, tangan, vektor, makanan, dan tanah. Menurut analisa peneliti menyatakan bahwa adanya hubungan kondisi jamban terhadap kebiasaan buang air besar sembarangan dikarenakan masih banyaknya masyarakat yang memiliki jamban yang tidak sehat seperti jarak jamban ke septic tank $\leq 10$ meter. Kelurahan Laksamana merupakan pemukiman yang padat dan banyak rumah yang berdekatan sehingga sulit untuk membuat jarak jamban yang memenuhi syarat dikarenakan lahan yang tidak mencukupi, jikapun jarak jamban ke septic tank $\geq 10$ meter hanya terdapat satu untuk keseluruhan rumah yang didapatkan dari pemerintah. Jika septic tank penuh maka akan menimbulkan bau yang tidak sedap. Hal lain yang membuat masyarakat untuk melakukan BABS adalah kondisi ekonomi masyarakat yang rendah dikarenakan masyarakat mayoritas bekerja sebagai buruh dan faktor pendidikan masyarakat yang hanya tamatan SMP, SMA bahkan ada yang tidak sekolah membuat masyarakat tidak mengetahui pentingnya jamban. Untuk itu, sebaiknya masyarakat membiasakan untuk membersihkan jamban setiap hari dan menjaga kebersihan lingkungan serta tidak melakukan kegiatan buang air besar sembarang.

\section{Hubungan Sumber Air Bersih (SAB) Terhadap Kebiasaan Buang Air Besar Sembarangan}

Dari hasil penelitian di dapatkan bahwa tidak ada hubungan yang bermakna antara sumber air bersih terhadap kebiasaan buang air besarsembarangan di Kelurahan Laksamana wilayah kerja Puskesmas Dumai Kota Tahun 2020. Hasil ini didukung dengani $\mathrm{p}$ value $=0,748$

Received: 30 April 2021, Accepted : Mai 2021 - Jurnal Photon Vol.11 No.2

DOI : https://doi.org/10.37859/jp.v11i2.2530

PHOTON is licensed under a Creative Commons Attribution-ShareAlike 4.0 International License 
$<\alpha 0,05$ dan $\mathrm{OR}=(0.800)$ artinya hal ini menunjukkan bahwa sumber air bersih tidak terdapat hubungan dengan kebiasaan buang air besar sembarangan. Dari hasil observasi peneliti pada responden di Kelurahan Laksamana hampir seluruh masyarakat memiliki sumber air yang bersih dikarenakan masyarakat sudah menggunakan air PAM yang telah diberikan oleh pemerintah. Pada observasi ini terdapat sumber air bersih yang memenuhi syarat sebesar 25 (55,8\%). Dilihat dari kuantitas di Indonesia air dibutuhkan sebanyak 138,5 liter/orang/hari, karena untuk mandi cuci dan kakus sebesar 12 liter, minum 2 liter, cuci pakaian 10,7 liter, kebersihan rumah 31,4 liter, taman 11,8 liter, cuci kendaraan 21,8 liter, wudhu 16,2 liter, dan lain lain sebanyak 33,3 liter. Dari segi kualitas meliputi parameter fisik, kimia, radioaktivitas, dan mikrobiologi yang memenuhi syarat kesehatan.

Hasil penelitian yang dilakukan oleh Bagoes, dkk (2019), menyatakan tidak ada hubungan ketersediaan sumber air bersih dengan kebiasaan buang air besar sembarangan dengan $\mathrm{P}$ value $=1,000>a 0,05$. Untuk ketersediaan air mudah untuk didapatkan karena masyarakat menggunakan air bersih yang telah disediakan untuk keperluan sehari-hari dan melakukan perebusan ketika air akan diminum.

Dengan memenuhi syarat pada kondisi air bersih, berarti hal ini telah sesuai dengan persyaratan akan air bersih dimana menurut Peraturan Menteri Kesehatan RI No. 416/Menkes/Per/IX/1990 mengenai syarat-syarat air bersih dan pengawasan kualitas air yang menyatakan bahwa parameter fisik harus tidak berasa, tidak berwarna, tidak berbau, jernih, suhu yang baik, memiliki jumlah zat padat terlarut (TDS) yang rendah. Untuk parameter kimia dimana air harus bebas dari bakteri patogen yang berada di air tercemar, kemudian untuk parameter kimia air harus bebas dari bahan kimia berbahaya seperti derajat keasaman $(\mathrm{pH})$, besi ( $\mathrm{Fe})$, alumunium ( $\mathrm{Al})$, dan lainnya yang akan memberikan dampak negatif untuk derajat kesehatan manusia. Air merupakan elemen yang sangat penting bagi perikehidupan makhluk hidup. Tanpa air, berbagai proses kehidupan tidak dapat berlangsung. Air digunakan untuk memenuhi kebutuhan sehari-hari seperti minum, mandi, memasak, mencuci, dan kegiatan lainnya. Oleh karena itu, penyediaan air merupakan salah satu kebutuhan utama bagi manusia untuk kelangsungan hidup dan menjadi faktor penentu dalam kesehatan dan kesejahteraan manusia.

Menurut analisa peneliti menyatakan bahwa tidak adanya hubungan sumber air bersih terhadap kebiasaan buang air besar sembarangan di Kelurahan Laksamana.Untuk mendapatkan air bersih di daerah tersebut air mudah untuk didapatkan dikarenakan masyarakat menggunakan air PAM untuk melakukan kegiatan termasuk mandi dan mencuci. Untuk dikonsumsi sebagai air minum masyarakat memasak air terlebih dahulu dan tidak menggunakan air sungai sebagai air minum, faktor lain yang membuat masyarakat malakukan aktivitas BABS adalah tingkat pendidikan Masyarakat kebanyakan SD-SMP dan rendahnya pengetahuan yang akan didapatkan tidak bertambah, dan dikarenakan faktor kebiasaan maka masyarakat yang memiliki pengetahuan baik dengan

Received: 30 April 2021, Accepted : Mai 2021 - Jurnal Photon Vol.11 No.2

DOI : https://doi.org/10.37859/jp.v11i2.2530

PHOTON is licensed under a Creative Commons Attribution-ShareAlike 4.0 International License 
kondisi sumber air bersih memenuhi syarat lama kelamaan akan ikut melakukan BABS. faktor kenyamanan juga berpengaruh, dan kondisi lingkungan yang sering terjadi seperti banjir air pasang yang membuat masyarakat dapat melakukan BABS karena lebih peraktis sehingga masyarakat tidak harus melakukan BAB di jamban.

\section{Hubungan Pengetahuan Terhadap Kebiasaan Buang Air Besar Sembarangan}

Dari hasil penelitian di dapatkan bahwa ada hubungan yang bermakna antara Pengetahuan terhadap kebiasaan buang air besar sembarangan di Kelurahan Laksamana wilayah kerja Puskesmas Dumai Kota Tahun 2020. Hasil ini didukung dengan $\mathrm{p}$ value $=0,031$

$<$ a 0,05 dan OR sebesar (2.778) artinya masyarakat dengan pengetahuannya rendah beresiko 2.778 kali untuk Buang Air Besar Sembarangan dibandingkan dengan masyarakat pengetahuan yang tinggi. Berdasarkan hasil observasi penelitian di Kelurahan Laksamana tidak seluruhnya masyarakat yang memiliki pengetahuan yang baik. Hasil observasi peneliti terdapat responden yang memiliki pengetahuan rendah sebesar 32 (64.0\%) dengan pengetahuan masyarakatnya yang masih rendah, berarti potensi melakukan kebiasaan BABS semakin besar. Masyarakat yang masih melakukan BABS disebabkan karena tingkat pengetahuan yang rendah tentang akibat dari BABS, dan hal ini dikarenakan masih minimnya pengetahuan dan informasi masyarakat dalam pemanfaatan jamban keluarga yang sehat disebakan masyarakat kebanyakan memiliki pendidikan SD-SMP serta dari pekerjaan banyak yang diluar sehingga ada potensi melakukan BABS. Sedangkan masyarakat yang memiliki pengetahuan tinggi seharusnya berperilaku $\mathrm{BAB}$ dijamban tetapi masih ada juga masyarakat tersebut yang melakukan BABS dimana memiliki WC tetapi dialirkan ke sungai.

Hasil penelitian Abrori (2016), menyatakan bahwa ada hubungan signifikan pengetahuan dengan perilaku Buang Air Besar Sembarangan diproleh dengan $\mathrm{p}$ value $=0,008$

$<a$ 0,05 yang artinya terdapat hubungan antara tingkat pengetahuan dengan perilaku Buang Air Besar Sembarang di Desa Rasau Jaya Dua Kecamatan Rasau kabupaten Kubu Raya. Responden dengan pengetahuan rendah memiliki resiko perilaku 0.331 kali lebih banyak dari berperilaku BABS dari responden dengan pengetahuan yang baik.

Hasil penelitian Widowati (2015), menyatakan bahwa ada hubungan yang signifikan pengetahuan dengan perilaku buang air besar sembarangan (BABS). Pengetahuan diperoleh $p$ value $=0,000<a 0,05$, artinya terdapat hubungan antara tingkat pengetahuan dengan perilaku Buang Air Besar Sembarangan (BABS) di Wilayah Kerja Puskesmas Sambungmacan II Kabupaten Sragen. Responden dengan pengetahuan rendah memiliki resiko perilaku 3,255 kali lebih besar untuk berperilaku Buang Air Besar Sembarangan (BABS) dari pada responden dengan pengetahuan tinggi.

Received: 30 April 2021, Accepted : Mai 2021 - Jurnal Photon Vol.11 No.2

DOI : https://doi.org/10.37859/jp.v11i2.2530

PHOTON is licensed under a Creative Commons Attribution-ShareAlike 4.0 International License 
Pengetahuan adalah hasil tahu dari seseorang terhadap objek melalui indera yang dimilikinya.pengetahuan seseorang tidak mempunyai dasar untuk mengambil keputusan dan menentukan tindakan masalah yang akan dihadapinya. Pengetahuan atau kognitif merupakan domain yang sangat penting untuk terbentuknya tindakan seseorang (Overt Behavior). Menurut Notoatmodjo (2011).

Menurut analisa peneliti menyatakan bahwa ada hubungan antara pengetahuan responden terhadap kebiasaan BABS dikarenakan beberapa faktor yaitu, pendidikan, sebagian masyarakat memiliki pendidikan dan pengetahuan yang rendah sehingga tidak diaplikasikan dengan baik serta minimnya informasi masyarakat dalam pemanfaatan jamban keluarga yang sehat. Untuk itu sebaiknya para petugas kesehatan memberikan penyuluhan agar masyarakat tahu dan mendapatkan pengetahuan yang baik tentang akibat BABS, agar masyarakat tidak melakukan kebiasaan BABS.

\section{Hubungan Sikap Terhadap Kebiasaan Buang Air Besar Sembarangan}

Dari hasil penelitian didapatkan bahwa ada hubungan yang bermakna antara sikap terhadap kebiasaan buang air besar sembarangan di Kelurahan Laksamana wilayah kerja Puskesmas Dumai Kota Tahun 2020. Hasil ini didukung dengan $\mathrm{p}$ value $=0,004<a$ 0,05 dan OR sebesar (3.943) yang artinya masyarakat dengan sikap yang negatif beresiko 3.943 kali untuk Buang Air Besar Sembarangan dibandingkan dengan masyarakat memiliki sikap yang positif.

Dari hasil observasi terhadap responden banyak yang memiliki sikap apatis dan tidak peduli terhadap BAB di jamban. Hal ini dikarenakan masyarakatnya sejak awal keberadaannya dekat dengan sungai dan rawa-rawa, ketika lingkungan terjadi air pasang masyarakat dengan mudah dan lebih prakis telah memanfaatkan untuk BABS dan tempat pembuangan tinja masyarakat yang tidak memiliki septic tank yang dilarikan ke sungai. Masyarakat ada yang merasa nyaman untuk melakukan BABS walaupun dirumah mereka telah memiliki sarana jamban yang baik. Hasil penelitian Pambudi (2019), bahwa ada hubungan signifikan sikap dengan kebiasaan Buang Air Besar Sembarangan diprolehnilai $\mathrm{p}$ value $=0,001<0,05$, yang artinya ada hubungan antara sikap dengan kebiasaan buang air besar sembarangan. Dengan nilai RP 1,8 yang artinya sikap yang kurang baik mempunyai risiko perilaku buang air besar sembarangan 4,8 kali lebih besar dibandingkan dengan seseorang yang bersikap baik.

Hasil penelitian Abrori (2016), bahwa ada hubungan signifikan sikap dengan kebiasaan Buang air besar sembarangan diproleh $\mathrm{p}$ value $=0,291<0,05$, yang artinya ada hubungan antara sikap dengan kebiasaan buang airbesar sembarangan Rasau Jaya Dua Kecamatan Rasau kabupaten Kubu Raya, dengan kebiasaan buang air besar sembarangan 3,2 kali lebih sering buang air besar sembarangan dari responden yang mempunyai sikap mendukung.

Received: 30 April 2021, Accepted : Mai 2021 - Jurnal Photon Vol.11 No.2

DOI : https://doi.org/10.37859/jp.v17i2.2530

PHOTON is licensed under a Creative Commons Attribution-ShareAlike 4.0 International License 
Sikap merupakan reaksi atau respon yang masih tertutup dariseseorang terhadap suatu stimulus atau objek. Sikap merupakan hal penting dalam kehidupan sehari-hari, karena jika sikap sudah terbentuk dalam diri seseorang maka sikap akan menentukan tingkah laku terhadap sesuatu. Sikap agar menjadi suatu perubahan nyata perlu adanya kondisi tertentu yang memungkinkan antara lain adanya fasilitas dan dukungan (Notoatmodjo, 2012).

Menurut analisa peneliti menyatakan bahwa ada hubungan antara sikap responden terhadap kebiasaan buang air besar sembarangan dikarenakan beberapa faktor yaitu kondisi lingkungan yang dekat dengan sungai, letak kondisi rumah yang padat dan berdekatan dengan pinggiran kota sehingga lahan untuk membuat septic tank terbatas, kebiasaan yang dilakukan oleh masyarakat sejak lama dan sudah menjadi tradisi dan budaya di masyarakat. Sebaiknya untuk petugas kesehatan memberikan penyuluhan mengenai akibat BABS, agar masyarakat bisa mengurangi sikap yang buruk dan tidak melakukan BABS lagi.

\section{Hubungan Pendapatan Terhadap kebiasaan Buang Air Besar Sembarangan}

Dari hasil penelitian di dapatkan bahwa ada hubungan yang bermakna antara pendapatan terhadap kebiasaan buang air besarsembarangan di Kelurahan Laksamana wilayah kerja Puskesmas Dumai Kota Tahun 2020. Hasil ini didukung dengan nilai $\mathrm{p}$ value $=0,005<\alpha(0,05)$ dan $\mathrm{OR}$ sebesar (3.739) artinya masyarakat dengan pendapatan yang rendah beresiko 3.739 kali untuk Buang Air Besar Sembarangan dibandingkan dengan masyarakat memiliki pendapatan yang tinggi.

Dari hasil observasi terhadap responden banyak yang memiliki pendapatan rendah dan mempunyai kebiasaan BABS. Hal ini dikarenakan masyarakatnya memiliki mayoritas pekerjaan buruh dengan status ekonominya rendah sehingga masyarakat tidak mampu membuat jamban yang layak serta membuat saluran septic tank, dan akhirnya mereka memilih melakukan BABS.

Hasil penelitian Widowati (2015) bahwa ada hubungan yang signifikan pendapatan dengan perilaku Buang Air Besar Sembarangan (BABS). Pendapatan diperoleh $\mathrm{p}$ value $=0,000<0,05$. Terlihat pada aspek pendapatan, responden yang penghasilan rendah persentase kebiasaan BABS lebih besar dibanding penghasilan tinggi dan secara statistik ada hubungan bermakna antara penghasilan pada perilaku Buang Air Besar Sembarangan (BABS). Responden dengan pendapatan rendah memiliki risiko perilaku 9,500 kali lebih besar untuk berperilaku Buang Air Besar Sembarangan (BABS) dari pada responden dengan pendapatan tinggi (OR: 9,500; 95\% CI:4,008-22,517).

Hasil Penelitian Nina (2019), bahwa ada hubungan yang signifikan pendapatan dengan perilaku Buang Air Besar Sembarangan (BABS). Pendapatan diperoleh $\mathrm{p}$ value $=0,004<0,05$, artinya ada hubungan antara 
pendapatan dengan buang air besar sembarangan. Responden dengan pendapatan yang redah berisiko 3,7 kali lebih besar untuk perlaku buang air besar sembarangan.

Pendapatan sebagai kemampuan rumah tangga atau perorangan untuk memperoleh barang atau jasa, kemampuan ini diukur dari tingkat harga pada saat memperoleh barang dan jasa. Pendapatan yang diperoleh seseorang mempengaruhi gerak hidup dan reaksinya ditengah masyarakat sebab besar kecilnya pendapatan akan mempengaruhi daya beli terhadap pemenuhan kebutuhan hidup pendapatan adalah seluruh penerimaan baik berupa uang maupun barang baik dari pihak luar maupun dari hasil sendiri, dengan jalan dinilai sejumlah harga atas atas barang yang berlaku pada saat itu dalam bentuk uang (Pinem, 2016).

Menurut analisa peneliti menyatakan bahwa ada hubungan antara pendapatan responden terhadap kebiasaan buang air besar sembarangan dikarenakan beberapa faktor pada variabel pendapatan ditunjukkan dengan masyarakat yang pada umumnya berada pada tingkat perekonomian rendah, dan pekerjaan mayoritas masyarakatnya seorang buruh, petani dan nelayan sehingga sulit untuk membangun fasilitas jamban dan septic tank. Masyarakat juga menyatakan bahwa ketiadaan uang untuk ditabung sehubungan dengan menurunnya pendapatan (karena krisis ekonomi) sehingga berpengaruh pada penggunaan maupun pemanfaatan jamban. Untuk itu pemerintah harus memperhatikan masyarakat yang berada dalam perekonomian rendah sehingg masyarakat dapat memanfaatkan jamban dan septic tank yang memenuhi syarat.

\section{Conclusion}

Berdasarkan hasil penelitian dan pembahasan yang telah dilakukan masih ditemukan sanitasi dasar yang belum memenuhi syarat, pengetahuan yang masih rendah, dan perilaku yang belum dapat berubah yang mengakibatkan masyarakat masih melakukan BABS. maka dapat ditarik kesimpulan sebagai berikut, Ada hubungan yang bermakna antara kondisi jamban terhadap kebiasaan buang air besar sembarangan (BABS). OR (95\%CI =3.617, Tidak ada hubungan yang bermakna antara sumber air bersih (SAB) terhadap kebiasaan buang air besar sembarangan $(\mathrm{BABS})$. OR $(95 \% \mathrm{CI}=0.800$, Ada hubungan yang bermakna antara pengetahuan responden terhadap kebiasaan buang air besar sembarangan (BABS). OR (95\%CI $=2.778$, Ada hubungan yang bermakna antara sikap responden terhadap kebiasaan buang air besar sembarangan (BABS). OR $(95 \% \mathrm{CI}=3.943$. Ada hubungan yang bermakna antara pendapatan responden terhadap kebiasaan buang air besar sembarangan (BABS). OR $(95 \% \mathrm{CI}=3.739$.

\section{Acknowledgement}

Terima kasih kepada Kepala Kelurahan Laksmana berserta Staf, Kepala Puskesmas Dumai Kota beserta Staf

Received: 30 April 2021, Accepted : Mai 2021 - Jurnal Photon Vol.11 No.2

DOI : https://doi.org/10.37859/jp.v17i2.2530

PHOTON is licensed under a Creative Commons Attribution-ShareAlike 4.0 International License 


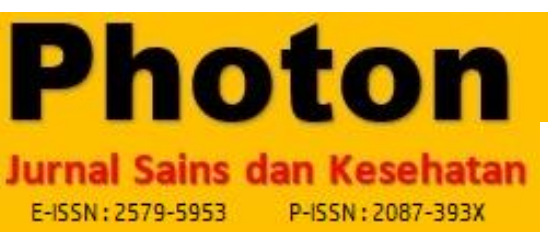

http://ejurnal.umri.ac.id/index.php/photon

Puskesmas Dumai Kota yang telah memberi izin dan membantu untuk menyelesaikan penelitian ini. Seluruh Masyarakat Keluarahan Laksmana yang telah meluangkan waktu untuk bisa di wawancara sehingga penelitian dapat diselesaikan.

\section{References}

Andrian Marwanto, Netrian, M. (2019). Hubungan tingkat pengetahuan dan sikap dengan pelaksanaan sanitasi total berbasis masyarakat (stbm) pilar pertama di wilayah kerja uptd puskesmas perawatan ratu agung kelurahan pematang gubernur kota bengkuluRelationshipOf Knowledge And Attitude Level W, 7(1), 1-6.

Anggoro, Febri.F.,\&Khoiron. (2015). Analisis Faktor yang Berhubungan Dengan Pemanfaatan Jamban Di Kawasan Perkebunan Kopi. e-Jurnal Pustaka Kesehatan, Vol3 :Jember

Abrori. (2016). Hubungan Pengetahuan, Sikap, Sosial Ekonomi, dan Penyediaan Jamban Keluarga Dengan Kebiasan Buang Air Besar Sembarangan di Desa Rasau Jaya2, 13(1), 18-25.

Bagoes, Wijarno. (2019). Faktor-Faktor yang Mempengaruhi Pemanfaatan Jamban Keluarga di kecamatan Jatibarang Brebes.

Fatonah, N. S. (2015). Partisipasi Masyarakat Dalam Pelaksanaan Program Sanitasi Total Berbasis Masyarakat Pilar Pertama ( Stop Babs ) Di Desa Purwosari Kecamatan Sayung Kabupaten Demak, 1-90.

Hadiati Sukma, Mursid, N. (2018). Hubungan Pengetahuan, Sikap Bab, Dan Kepemilikan Septic Tank Dengan Status Odf (Open Defecation Free) Di Kecamatan Candisari Kota Semarang. Jurnal Kesehatan Masyarakat (eJournal), 6(6), 143-149.

Hayana, Marlina, H., \& Kurnia, A. (2018). Hubungan Karakteristik Individu dan Lingkungan SosialTerhadap Perilaku Buang AirBesarSembarang. Jurnal Kesehatan Komunitas, 4 (1), 8-15.

Husna, S. M. (2018). Majalah Kesehatan Masyarakat Aceh ( MaKMA ), 1(1), 27-33.

Kemenkes RI. Kurikulum dan Modul Pelatihan Sanitasi Total Berbasis Masyarakat (STBM). Jakarta: Kementerian Kesehatan RI; 2014

Kholid,A.(2017).Promosi Kesehatan Dengan Pendekatan Teori Prilaku,Media, dan Aplikasinya. Depok : Rajawali Pers.

Mundiatun, Daryanto M.Si. (2015). Pengelolaan Kesehatan Lingkungan. Yogyakara: Gava Media

Nina. (2019). Hubungan pengetahuan, Saran, dan Sosial Ekonomi dengan Kebiasaan Buang Air Besar Sembarangan.Artikel Penelitian

Notoatmodjo. S. (2011). Kesehatan Masyarakat Ilmu dan Seni. Jakarta: Rineka Cipta.

Pambudi, Adam.,S. (2019). Hubungan karakteristik penduduk dengan perilaku buang air besar sembarangan

Received: 30 April 2021, Accepted : Mai 2021 - Jurnal Photon Vol.11 No.2

DOI : https://doi.org/10.37859/jp.v11i2.2530

PHOTON is licensed under a Creative Commons Attribution-ShareAlike 4.0 International License 
(babs) di desa kenongorejo kecamatan pilangkenceng kabupaten madiun Oleh, 4(1), 75-84.

Profil Dinas Kesehatan Kota Dumai. (2019) Profil Puskesmas Dumai Kota. (2019)

Pinem, M. (2016). Pengaruh pendidikan dan status sosial ekonomi kepala keluarga bagi kesehatan lingkungan masyarakat. Jurnal Ilmu Pemerintahan Dan Sosial Politik UMA, 4(1), 97-106. Retrieved from http://ojs.uma.ac.id/index.php/jppuma

Sumantri, Arif., H. (2010). Kesehatan Lingkungan. Jakarta: Kencana Prenada Media Group 